\title{
A New "Intersection" Method for Multi-Objective Optimization in Material Selection
}

\author{
Maosheng Zheng*, Yi Wang, Haipeng Teng
}

\begin{abstract}
Till now the previous methods for multi-objective optimization adopt the "additive" algorithm for the normalized evaluation indexes, which has the inherent shortcoming of taking the form of "union" in the viewpoint of set theory. In fact, "simultaneous optimization of multiple indexes" should be more appropriate to take the form of "intersection" for the normalized evaluation indexes in the respects of set theory and "joint probability" in probability theory. In this paper, a new concept of favorable probability is proposed to reflect the favorable degree of the candidate material in the selection; All material property indicators are divided into beneficial or unbeneficial types to the material selection; Each material property indicator correlates to a partial favorable probability quantitatively, and the total favorable probability of a candidate material is the product of all partial favorable probabilities in the viewpoints of "intersection" of set theory and "joint probability" in probability theory, which is the sole decisive index in the competitive selection process. Results of the application examples indicate the validity of the new method.
\end{abstract}

Keywords: favorable probability; material selection; multi-objective optimization; probability theory; quantitative assessment

\section{INTRODUCTION}

At present, there are more than 40,000 useful metal alloys and non-metal engineering materials in the world [1]. These large amounts of materials form a material library, which is available to designers and engineers together with many manufacturing processes and selection attributes (maybe conflicting with each other). Due to its complexity, it makes material selection an uneasy task.

Therefore, a commonly quantitative assessment for material selection is needed for the appropriate design and application of material in engineering.

It has been more than 40 years since the early work in material selection [2], a series of methods have been developed to analyze the big amount of data involved in material selection process so as to obtain a systematic result.

Farag et al proposed an integrated approach to the interrelated activities of product design, materials selection and cost estimation [1]. The wide range of engineering materials is first narrowed to a limited number of candidates using design limitations and performance requirements. Each of the candidate materials is used to develop an optimum design which is then used in cost estimation. An optimization technique, i.e. benefit - cost analysis, is used to select the optimum design - material combination for the initial screening of materials. This method is lacking of quantitative comparison of other attributes, such as difficulty of manufacturing and processing technique, environment, etc. In his book [2], the performance index method is introduced, which is an alternative form of the weighted property method in aiming to overcome the drawback of combining unlike units together in the original weighted property method by introducing scaling factors [2]. However, in the scaling process the scaled value is proportional to normal material property value for the beneficial material property index, but the scaled value of the unbeneficial material property index is in reverse ratio to the normal material property value, which obviously sets the beneficial property index and unbeneficial property index in a nonequivalent or unconformable manner [2].
Ashby developed material selection charts for a wide range of materials. Two performance indices are shown in a chart [3]. A wide range of physical properties of materials (i.e. electronic conductivity, elastic modules, etc.) are correlated to the interstice parameters (i.e. density, heat capacity, etc.) empirically in the chart, which is suitable for the initial screening of materials due to the lacking of effective comparison of other indexes, such as processing technique and difficulty of manufacturing, environment, etc.

Analytical Hierarchy Process (AHP) was developed by Saaty, AHP is a theory of measurement through pairwise comparisons that relies on the judgments of experts to give priority scales. Through these scales the intangibles are measured relatively. The comparison is made using an absolute judgment scale, which indicates the degree to which one element dominates another element in terms of a given attribute. Obviously, in order to conduct the scaling process, the denominator is subjectively selected, which affects the value of each decision matrix element and determines the final result of the comparison. Different scaling algorithm, the such as vector normalization, linear scale method, extreme value processing method, and standard deviation normalization method, etc., will lead to different result [4].

Vlšekriterijumsko KOmpromisno Rangiranje (VIKOR) method was developed by Opricovic, which determines the compromise ranking-list, the compromise solution, and the weight stability intervals for preference stability of the compromise solution obtained with the initial (given) weights. The multi-criteria ranking index $Q$ is proposed on basis of the particular measure of "closeness" to the "virtual ideal solution", besides an artificial weighting factor $v$ is introduced in evaluation procedure of VIKOR value $Q$. [5].

Technique of ranking Preferences by Similarity to the Ideal Solution (TOPSIS) was proposed by Hwang and Yoon originally in 1981, and further developed by Chen and Hwang in 1992 [6]. The TOPSIS method introduces two "virtual ideal points", i.e., the so called a "positive ideal solution" and a "negative ideal solution". TOPSIS method determines the best alternative by minimizing the distance to the ideal positive solution and maximizing the distance to the 
negative ideal solution. In addition, a scaled decision matrix and Euclidean distances are utilized in TOPSIS to measure the alternatives with their positive ideal solution and negative ideal solution. The preference order of alternatives is obtained through ranking the Euclidean distances. The validity of the "virtual ideal points" and the denominator in the scaling is not clarified.

Multi-Objective Optimization on the basis of Ratio Analysis (MOORA) for discrete alternatives was developed by Brauers, el al. [7]. This method depends on a ratio system in which each response of an alternative on an objective is divided by a denominator, which is representative for all alternatives concerning that objective. Furthermore, these responses are added in case of maximization and subtracted in case of minimization for the optimization. Obviously, in MOORA, the reasonability of the selection for the denominator to each response of an alternative and the algorithm of "added in case of maximization and subtracted in case of minimization" in final optimization procedure are unclear.

From above discussion, it can be seen that since the introduction of artificial factors or subjective denominator in the scaling process for the normalization of decision matrix in some methods, the relevant algorithms could not be seen as complete quantitative ones, which are at most semi quantitative approaches in some sense. Besides, the treatment for beneficial property index and unbeneficial property index is not equivalent and conformable in some approaches. On the other hand, the previously proposed methods for multiobjective optimization adopt especially "additive" algorithm after parameterization and scaling of the evaluation indexes to get the final unified indicator for the candidate. From the perspective of "simultaneous optimization of multiple indexes", which is equivalent to taking the form of "union" in set theory [8], it has the shortcomings inherently. In fact, from the points of view of set theory and probability theory, "simultaneous optimization of multiple indexes" should be more appropriate to take the form of "intersection" and "joint probability" for the evaluation indexes [8]. Therefore, comprehensive study in materials selection is still needed so as to develop a quantitative and overall approach.

The motivation of this research for the multi-objective optimization is from the "simultaneous optimization of multiple indexes" that corresponds to "intersection" method in the point of view of set theory. In this paper, a new "intersection" method for multi-objective optimization in material selection is developed on basis of set theory and probability theory. A new concept of favorable probability is introduced, and the total favorable probability of a candidate material is the product of the partial favorable probabilities of all possible material property indicators for the candidate material in the point of view of probability theory, which is the overall consideration of all possible material property indicators. The total favorable probability of a candidate material is the decisive index for the material to get victory in the selection process.

\section{A NEW "INTERSECTION" METHOD FOR MULTI- OBJECTIVE OPTIMIZATION ON BASIS OF PROBABILITY THEORY \\ 2.1 Concept of Favorable Probability for Material Selection}

Usually, a material exhibits many features in different sides; each material property indicator could reflect one aspect of the material characteristics in some sense. Some material property indicators might be beneficial to the material selection, but other property indicators are unbeneficial (cost) to the material selection. In fact, an actual material is the integral body of both beneficial and unbeneficial indicators to the material selection and utilization. It is not possible for a material to have only full beneficial or unbeneficial property indicators to the material selection and utilization. So, an overall consideration for material selection is needed in the viewpoint of impersonal analysis, which makes the material selection a systemic and comprehensive task. Therefore, both beneficial and unbeneficial (cost) indicators should be dealt with properly, so as to propose an integral and overall consideration to the material selection quantitatively.

Take the design and manufacture of a flight as an example, the strength and ductility of a candidate material are the beneficial indicators for the material selection, while the specific gravity (density) is unbeneficial indicator to the material selection. The beneficial indicators have the characteristics of the higher the better, while the unbeneficial (cost) indicators have the characteristics of the lower the better to the material selection.

Therefore, all the material property indicators are divided into two types, i.e., beneficial or unbeneficial (cost) types to the material selection naturally.

As a quantitative assessment to the term "the higher the better" and "the lower the better" for a material property indicator, a new concept of "favorable probability" can be introduced; the favorable degree of the material property indicator in the material selection competition can be characterized quantitatively by the favorable probability comparatively.

\subsection{Quantitative Assessments of Favorable Probability and Multi-Objective Optimization in Material Selection}

From the principle of simplicity, it assumes that the favorable probability of a material property indicator with the character of "the higher the better" (beneficial indicator) in the material selection process is positively correlative to this material property indicator linearly, i.e.

$P_{i j} \propto X_{i j}$,
$P_{i j}=\alpha_{j} X_{i j}, \quad i=1,2, \ldots, n ; j=1,2, \ldots, m$.

In Eq. (1), $X_{i j}$ represents the $j^{\text {th }}$ material property indicator of the $i^{\text {th }}$ candidate material; $P_{i j}$ is the partial favorable probability of the beneficial material property indicator $X_{i j} ; n$ is the total number of candidate materials in the material group involved; $m$ is the total number of material 
property indicators of each candidate material in the group; $\alpha_{j}$ is the normalized factor of the $j^{\text {th }}$ material property indicator.

Furthermore, according to the general principle of probability theory [8], the summation of each $P_{i j}$ for the index $i$ in $j^{\text {th }}$ material factor is normalized and equal to 1 , i.e., $\sum_{i=1}^{n} P_{i j}=1$, thus, it obtains naturally

$\sum_{i=1}^{n} \alpha_{j} X_{i j}=\sum_{i=1}^{n} P_{i j}=1, \alpha_{j}=\frac{1}{n \bar{X}_{j}}$

$\bar{X}_{j}$ is the average value of the $j^{\text {th }}$ material property indicator in the material group involved.

Equivalently and conformably, the partial favorable probability of the unbeneficial (cost) material property indicator $X_{i j}$ is negatively correlative to its material property indicator linearly, i.e.

$P_{i j} \propto\left(X_{j \max }+X_{j \min }-X_{i j}\right)$,

$P_{i j}=\beta_{j}\left(X_{j \max }+X_{j \min }-X_{i j}\right), \quad i=1,2, \ldots, n ; j=1,2, \ldots, m .(3)$

In Eq. (3), $X_{j \max }$ and $X_{j \min }$ represent the maximum and minimum values of the material property indicator $X_{j}$ in the material group, respectively; $\beta_{j}$ is the normalized factor of the $j^{\text {th }}$ material property indicator.

Correspondingly, by using the normalization principle of probability theory generally [8], it obtains ordinarily

$\beta_{j}=\frac{1}{\left[n\left(X_{j \max }+X_{j \min }\right)-n \bar{X}_{j}\right]}$.

Furthermore, according to basic probability theory [8], the total / comprehensive favorable probability of the $i^{\text {th }}$ candidate material to be selected is the product of its partial favorable probability of each material property indicator $P_{i j}$, i.e., "joint probability" or "intersection" in set theory,

$P_{i}=P_{i 1} \cdot P_{i 2} \cdots P_{i m}=\prod_{j=1}^{m} P_{i j}$.

Finally, the total favorable probability of a candidate material is the sole decisive index and dominator for the material selection comparatively; the ranking of the candidate materials can be conducted according to their values of total favorable probability, which decides the winner of the material selection.

The main characteristics of our new "intersection" method for multi-objective optimization in material selection on basis of probability theory is that the treatment for both beneficial property index and unbeneficial property index is equivalent and conformable without any artificial factors or subjective scaling factor.

By far, the concept of favorable probability and its quantitative assessment as well as the new multi-objective optimization method for material selections are developed.

\section{APPLICATION OF THE NEW METHOD OF MULTI- OBJECTIVE OPTIMIZATION IN MATERIAL SELECTION 3.1 Material Selection for a Rectangular Beam}

Md Abdul Maleque once proposed a problem of material selection for a rectangular beam with a length of $0.5 \mathrm{~m}$ and width of $50 \mathrm{~mm}$, which is subjected to a concentrated load of $10 \mathrm{kN}$ acting in the middle of the beam [9]. There were four candidate materials for this rectangular beam design. Table 1 cites the material property indicators of the candidate materials in the rectangular beam design. The candidate materials shown in Tab. 1 could form a candidate material group for the selection process.

Table 1 Properties of candidate materials for the rectangular beam design [9]

\begin{tabular}{|c|c|c|c|}
\hline Materials & $\begin{array}{c}\text { Elastic modulus } \\
E(\mathrm{GPa})\end{array}$ & $\begin{array}{c}\text { Specific gravity } \\
d\left(\mathrm{~g} / \mathrm{cm}^{3}\right)\end{array}$ & $\begin{array}{c}\text { Relative cost } \\
C\end{array}$ \\
\hline Steel AISI 1020 & 207 & 7.86 & 1 \\
\hline Steel AISI 4140 & 210 & 7.86 & 1.5 \\
\hline Al 6061 T6 & 70 & 2.7 & 6 \\
\hline GFC & 25 & 2.11 & 9 \\
\hline
\end{tabular}

The material property indicator $E$ has the characteristic of the higher the better for this usage, so the factor $E$ is the beneficial property indicator to the material selection; while the specific gravity $d$ and the relative cost index $C$ are the unbeneficial material property indicators to the material selection, which have the characteristic of the lower the better. So, the assessment for partial favorable probabilities of beneficial or unbeneficial type material property indictors can be conducted according to Eqs. (1) and (2), or Eqs. (3) and (4), separately.

Tab. 2 shows the results of partial favorable probability $P_{i j}$ and the total favorable probabilities $P_{i}$ assessed for each material property indicators for the four candidate materials.

Table 2 Partial and total favorable probabilities of the candidate materials for the rectangular beam design

\begin{tabular}{|c|c|c|c|c|c|}
\hline Materials & $P_{i j}$ for $E$ & $P_{i j}$ for $d$ & $P_{i j}$ for $C$ & $P_{i} \times 100$ & Rank \\
\hline Steel AISI 1020 & 0.4043 & 0.1090 & 0.4000 & 1.7634 & 1 \\
\hline Steel AISI 4140 & 0.4102 & 0.1090 & 0.3778 & 1.6896 & 2 \\
\hline Al 6061 T6 & 0.1367 & 0.3757 & 0.1778 & 0.9132 & 3 \\
\hline GFC & 0.0488 & 0.4062 & 0.0444 & 0.0882 & 4 \\
\hline
\end{tabular}

It can be seen from the last column of Tab. 2 that the comparative result clearly shows the maximum value of total favorable probabilities $P_{i}$ being steel AISI 1020, so the optimal selection for the material of rectangular beam design is steel AISI 1020, which agrees with the common knowledge.

\subsection{Material Selection for Automotive Piston Design}

Md Abdul Maleque also raised a problem of material selection for automotive piston design [9]. Tab. 3 cites the material property indicators of the seven candidate materials in the automotive piston design [9]. The material property indicators 3, 4, 6 and 7 are beneficial indicators, and the 
material property indicators $1,2,5$ and 8 are unbeneficial indicators for the material selection, respectively. In addition, the material property indicators 6 and 7 are both the material strength indicators with the similar meaning and function, therefore the material factor 6 is taken into consideration here only.

Tab. 4 presents the results of partial favorable probabilities and the total favorable probability assessed for each material property indicator of the seven candidate materials.

Table 3 Material properties indicators of the candidate materials in automotive piston design [9]

\begin{tabular}{|c|c|c|c|c|c|c|c|c|}
\hline \multirow{3}{*}{ Material } & \multicolumn{8}{|c|}{ Material property factor } \\
\hline & 1 & 2 & 3 & 4 & 5 & 6 & 7 & 8 \\
\hline & $\begin{array}{c}\text { Friction } \\
\text { coefficient }\end{array}$ & $\begin{array}{c}\text { Wear rate } \\
\left(\times 10^{-6} \mathrm{~mm}^{3} / \mathrm{N} / \mathrm{m}\right)\end{array}$ & $\begin{array}{c}\text { Thermal capacity } \\
(\mathrm{kJ} / \mathrm{kg} \cdot \mathrm{K})\end{array}$ & $\begin{array}{l}\text { Thermal conductivity } \\
(\mathrm{W} / \mathrm{m} \cdot \mathrm{K})\end{array}$ & $\begin{array}{c}\text { Specific gravity } \\
\left(\mathrm{Mg} / \mathrm{m}^{3}\right)\end{array}$ & $\begin{array}{l}\text { Yield strength } \\
(\mathrm{MPa})\end{array}$ & $\begin{array}{c}\text { Tensile strength } \\
(\mathrm{MPa})\end{array}$ & $\begin{array}{c}\text { Relative } \\
\text { cost }\end{array}$ \\
\hline GCI & 0.41 & 2.36 & 0.46 & 80 & 7.2 & 460 & 455 & 1 \\
\hline Ti-alloy & 0.34 & 246.3 & 0.58 & 17.58 & 4.42 & 700 & 1014 & 20 \\
\hline Ni-alloy & 0.39 & 5.32 & 0.41 & 12.6 & 8.4 & 851 & 1100 & 17 \\
\hline Al-alloy & 0.36 & 2.89 & 0.714 & 190 & 2.73 & 480 & 510 & 10 \\
\hline AMC 1 & 0.35 & 3.25 & 0.98 & 155 & 2.7 & 276 & 310 & 2.8 \\
\hline AMC 2 & 0.44 & 2.91 & 0.92 & 180 & 2.8 & 425 & 485 & 2.6 \\
\hline TMC & 0.31 & 8.19 & 0.51 & 17.85 & 4.68 & 700 & 1029 & 20.5 \\
\hline
\end{tabular}

Table 4 Partial and total favorable probabilities of the candidate materials for automotive piston design

\begin{tabular}{|c|c|c|c|c|c|c|c|c|c|}
\hline Material & $P_{i j}$ for 1 & $P_{i j}$ for 2 & $P_{i j}$ for 3 & $P_{i j}$ for 4 & $P_{i j}$ for 5 & $P_{i j}$ for 6 & $P_{i j}$ for 8 & $P_{i} \times 10^{6}$ & Rank \\
\hline GCI & 0.1283 & 0.1676 & 0.1006 & 0.1225 & 0.0871 & 0.1182 & 0.2676 & 0.7301 & 4 \\
\hline Ti-alloy & 0.1547 & 0.0016 & 0.1268 & 0.0269 & 0.1492 & 0.1799 & 0.0196 & 0.0004 & 7 \\
\hline Ni-alloy & 0.1358 & 0.1656 & 0.0896 & 0.0193 & 0.0603 & 0.2187 & 0.0587 & 0.0301 & 5 \\
\hline Al-alloy & 0.1472 & 0.1673 & 0.1561 & 0.2930 & 0.1870 & 0.1233 & 0.1501 & 3.8700 & 3 \\
\hline AMC 1 & 0.1509 & 0.1670 & 0.2143 & 0.2374 & 0.1876 & 0.0709 & 0.2441 & 4.1642 & 2 \\
\hline AMC 2 & 0.1170 & 0.1672 & 0.2011 & 0.2756 & 0.1854 & 0.1092 & 0.2467 & 5.4180 & 1 \\
\hline TMC & 0.1660 & 0.1637 & 0.1115 & 0.0273 & 0.1434 & 0.1799 & 0.0131 & 0.0279 & 6 \\
\hline
\end{tabular}

Tab. 4 shows that the ranking order of this material selection is AMC $2>\mathrm{AMC} 1>\mathrm{Al}-$ alloy $>\mathrm{GCI}>\mathrm{Ni}-$ alloy $>\mathrm{TMC}>\mathrm{Ti}-$ alloy. The best material selected from this procedure is AMC 2, which coincides with the result of the semi-quantitative method - the so-called digital logic method accidentally [9], while the selection process of the latter is quite complex. The subsequent ranking for other candidate materials is not exactly the same as the result of the digital logic method due to the utilization of weighting factors and performance index method in the latter [9].

\subsection{Material Selection for Automotive Brake Pad Design}

Md Abdul Maleque's next example is the design of an automotive brake pad [9]. Tab. 5 cites the material property indicators of the four candidate materials in the automotive brake pad design [9]. The yield strength $Y$ is the beneficial material property indicator, while specific gravity $d$ and relative cost $C$ are unbeneficial (cost) type material property indicators in the material selection, individually.

Tab. 6 presents the results of partial favorable probabilities and the total favorable probability assessed for each material property indicator of the four candidate materials.

Table 5 Candidate materials for automotive brake pad design [9]

\begin{tabular}{|c|c|c|c|}
\hline Materials & $\begin{array}{c}\text { Specific gravity } d \\
\left(\mathrm{~g} / \mathrm{cm}^{3}\right)\end{array}$ & $\begin{array}{c}\text { Yield strength } Y \\
(\mathrm{MPa})\end{array}$ & $\begin{array}{c}\text { Relative } \\
\text { cost } C\end{array}$ \\
\hline Alumina whiskers & 3.8 & 300,000 & 3.5 \\
\hline CFRP & 2.0 & 544 & 4.5 \\
\hline 4340 Steel & 7.8 & 296 & 1 \\
\hline Al-alloy & 4.5 & 420 & 6 \\
\hline
\end{tabular}

Table 6 Partial and total favorable probabilities of the candidate materials for automotive brake pad design

\begin{tabular}{|c|c|c|c|c|c|}
\hline Materials & $P_{i j}$ for $d$ & $P_{i j}$ for $Y$ & $P_{i j}$ for $C$ & $P i \times 100$ & Rank \\
\hline Alumina whiskers & 0.2844 & 0.9958 & 0.2692 & 7.6238 & 1 \\
\hline CFRP & 0.3697 & 0.0018 & 0.1923 & 0.0128 & 2 \\
\hline 4340 Steel & 0.0948 & 0.0010 & 0.4615 & 0.0043 & 3 \\
\hline Al-alloy & 0.2512 & 0.0014 & 0.0769 & 0.0027 & 4 \\
\hline
\end{tabular}

From Tab. 6, it can be seen that Alumina whiskers is the appropriate material comparatively in the competition, which agrees with the elementary knowledge.

\subsection{Material Selection of Polymeric Nano-Composite Material for Automotive Bumper Beam}

Hasanzadeh et al studied the material selection of polymeric nano-composite material for automotive bumper beam by using multi-criteria decision making methods [10], including AHP - TOPSIS, AHP - MOORA, Entropy TOPSIS and Entropy - MOORA. Three PA-6 based nano composites with the codes of M-1, M-2 and M-3 and three PC based nano - composites with the codes of M-4, M-5 and M-6 were employed [10], the material property indicators including difficulty in manufacture and relative cost are cited in Tab. 7.

In Tab. 7, the relative cost of the raw materials was evaluated in range from highest value of 6 to the lowest value of 1 , and the difficulty of the manufacturing process was evaluated in range from most difficult with value of 6 to the easiest with value of 1 as well. The material property indicators of tensile strength and impact strength have the feature of beneficial indicators, and the material indicators of the relative cost and difficulty in manufacture have the nature of unbeneficial indicators for the material selection, individually. 
Table 7 Material property indicators of the 6 nano-composites

\begin{tabular}{|c|c|c|c|c|}
\hline Alternative & $\begin{array}{c}\text { Tensile strength } \\
(\mathrm{MPa})\end{array}$ & $\begin{array}{c}\text { Impact strength } \\
(\mathrm{MPa})\end{array}$ & $\begin{array}{c}\text { Relative } \\
\text { cost }\end{array}$ & $\begin{array}{c}\text { Difficulty in } \\
\text { manufacture }\end{array}$ \\
\hline M-1 & 25 & 113.07 & 4 & 1 \\
\hline M-2 & 37.55 & 103.54 & 5 & 2 \\
\hline M-3 & 34.79 & 96.51 & 6 & 3 \\
\hline M-4 & 135.38 & 224.58 & 1 & 4 \\
\hline M-5 & 141.71 & 154.06 & 2 & 5 \\
\hline M-6 & 141.92 & 133.53 & 3 & 6 \\
\hline
\end{tabular}

The ranking of the evaluation results by using the new quantitative method is shown in the second column of Tab. 8. In addition, the ranking of alternatives which were assessed by using other four methods are cited in subsequent columns of Tab. $8[10]$ as well.

Table 8 Ranking of the alternatives corresponding to the 5 assessments

\begin{tabular}{|c|c|c|c|c|c|}
\hline Alternative & $\begin{array}{c}\text { New } \\
\text { method }\end{array}$ & $\begin{array}{c}\text { AHP- } \\
\text { TOPSIS }\end{array}$ & $\begin{array}{c}\text { AHP- } \\
\text { MOORA }\end{array}$ & $\begin{array}{c}\text { Entropy- } \\
\text { TOPSIS }\end{array}$ & $\begin{array}{c}\text { Entropy- } \\
\text { MOORA }\end{array}$ \\
\hline M-1 & 4 & 4 & 4 & 4 & 4 \\
\hline M-2 & 5 & 5 & 5 & 5 & 5 \\
\hline M-3 & 6 & 6 & 6 & 6 & 6 \\
\hline M-4 & 1 & 1 & 1 & 1 & 1 \\
\hline M-5 & 2 & 2 & 2 & 2 & 2 \\
\hline M-6 & 3 & 3 & 3 & 3 & 3 \\
\hline
\end{tabular}

The assessment results for the ranking of the alternatives in Tab. 8 show a consistent consequence accidentally, but the new method is rather simple without any subjective factor.

\section{APPLICATION IN MULTI-OBJECTIVE TEST DESIGN}

The new multi-objective optimization method for material selection proposed in section 2 could be extended in application of multi-objective orthogonal test design and uniform experimental design due to the similarity of the problems.

In general, the multi-objective orthogonal test design is conducted by the so called "comprehensive balance method" or "comprehensive scoring method" [11], or "grey relational analysis" [12], signal to noise ratio analysis [13], which involve personal factors and are not full quantitative, but an empirical ones instead.

Cheng et al proposed a multi-objective robust optimization method based on parameter design using inner - outer array, analysis of signal to noise ratio (SNR) and the technique for order preference by similarity to ideal solution
(TOPSIS) [14]. Then formulation of the process parameter schemes is conducted on basis of uniform experimental design and stepwise regression analysis [14], which is rather complex in addition to the common problems of TOPSIS and SNR.

In this section, the new method developed in the section 2 is utilized to study the multi-objective orthogonal test design and uniform experimental design so as to extend its application in optimal design quantitatively.

\subsection{Multi-Objective Optimization Design on Extrusion Process for Joint Bearing}

Xin et al. conducted the multi-objective optimization on extrusion process for joint bearing by FEM software [11], it involves three input variables and four levels, i.e., extrusion groove depth and width of bearing outer ring and the feeding amount of mold as the input variables. The bearing crevice $\Delta t$, the maximum extrusion force $F_{\max }$ and the maximum contact pressure $P_{\max }$ of liner are taken as the indicators of the multi targets by using orthogonal test design with the help of comprehensive balance analysis method [11].

The indicators $\Delta t, F_{\max }$ and $P_{\max }$ are all unbeneficial indicators to the technique optimization, therefore, Eqs. (3) and (4) are employed to perform the assessment for their partial favorable probability.

Tab. 9 cites the results of the orthogonal test design optimization on extrusion process for joint bearing [11]. Tab. 10 presents the results of the test and the partial favorable probabilities as well as total favorable probabilities for bearing tightness, the maximum extrusion force and the maximum contact pressure of liner.

In Tab. 10, the test 4 exhibits the maximum of the total favorable probability $P_{i}$, it could be chosen as one of the optimal combination in the multi-objective orthogonal test design directly.

Table 9 Factors and levels of the orthogonal test design optimization on extrusion process for joint bearing [11]

\begin{tabular}{|c|c|c|c|}
\hline \multirow{2}{*}{ Levels } & \multicolumn{3}{|c|}{ Process factors } \\
\cline { 2 - 4 } & $\begin{array}{c}\text { Groove depth } \\
d(\mathrm{~mm})\end{array}$ & $\begin{array}{c}\text { Groove width } \\
h(\mathrm{~mm})\end{array}$ & $\begin{array}{c}\text { Feeding amount of mold } \\
l(\mathrm{~mm})\end{array}$ \\
\hline 1 & 0.28 & 7.6 & 6.35 \\
\hline 2 & 0.42 & 9.1 & 6.40 \\
\hline 3 & 0.56 & 10.6 & 6.45 \\
\hline 4 & 0.70 & 12.1 & 6.50 \\
\hline
\end{tabular}

Table 10 Results of orthogonal test design for optimization on extrusion process for joint bearing [11]

\begin{tabular}{|c|c|c|c|c|c|c|c|c|c|c|c|}
\hline \multirow{2}{*}{ Test No. } & \multicolumn{3}{|c|}{ Process factors } & \multicolumn{3}{|c|}{ Objective indicator } & \multicolumn{3}{|c|}{ Partial favorable probability } & \multirow{2}{*}{$\begin{array}{l}\text { Total favorable probability } \\
P_{i} \times 10^{4}\end{array}$} & \multirow[b]{2}{*}{ Rank } \\
\hline & $d$ & $h$ & $l$ & $\Delta t(\mathrm{~mm})$ & $F_{\max }(\mathrm{kN})$ & $P_{\max }(\mathrm{MPa})$ & $P_{i j}$ for $\Delta t$ & $P_{i j}$ for $F_{\max }$ & $P_{i j}$ for $P_{\max }$ & & \\
\hline 1 & 1 & 1 & 1 & 0.019 & 108 & 481 & 0.0774 & 0.0550 & 0.0630 & 2.6818 & 9 \\
\hline 2 & 1 & 2 & 2 & 0.011 & 107 & 506 & 0.0925 & 0.0558 & 0.0598 & 3.0850 & 5 \\
\hline 3 & 1 & 3 & 3 & 0.014 & 97 & 465 & 0.0868 & 0.0629 & 0.0650 & 3.5483 & 3 \\
\hline 4 & 1 & 4 & 4 & 0.014 & 87 & 431 & 0.0868 & 0.0701 & 0.0693 & 4.2109 & 1 \\
\hline 5 & 2 & 1 & 2 & 0.021 & 113 & 537 & 0.0736 & 0.0515 & 0.0560 & 2.1192 & 10 \\
\hline 6 & 2 & 2 & 1 & 0.018 & 100 & 469 & 0.0792 & 0.0608 & 0.0645 & 3.1051 & 4 \\
\hline 7 & 2 & 3 & 4 & 0.021 & 98 & 500 & 0.0736 & 0.0622 & 0.0606 & 2.7732 & 8 \\
\hline 8 & 2 & 4 & 3 & 0.026 & 76 & 376 & 0.0642 & 0.0779 & 0.0762 & 3.8066 & 2 \\
\hline 9 & 3 & 1 & 3 & 0.03 & 120 & 599 & 0.0566 & 0.0465 & 0.0482 & 1.2671 & 15 \\
\hline 10 & 3 & 2 & 4 & 0.025 & 114 & 600 & 0.0660 & 0.0508 & 0.0481 & 1.6105 & 12 \\
\hline 11 & 3 & 3 & 1 & 0.03 & 83 & 415 & 0.0566 & 0.0729 & 0.0713 & 2.9412 & 6 \\
\hline 12 & 3 & 4 & 2 & 0.037 & 71 & 349 & 0.0434 & 0.0815 & 0.0795 & 2.8130 & 7 \\
\hline 13 & 4 & 1 & 4 & 0.04 & 125 & 656 & 0.0378 & 0.0429 & 0.0410 & 0.6640 & 16 \\
\hline
\end{tabular}


Table 10 Results of orthogonal test design for optimization on extrusion process for joint bearing [11] (continuation)

\begin{tabular}{|c|c|c|c|c|c|c|c|c|c|c|c|}
\hline \multirow{2}{*}{ Test No. } & \multicolumn{3}{|c|}{ Process factors } & \multicolumn{3}{|c|}{ Objective indicator } & \multicolumn{3}{|c|}{ Partial favorable probability } & \multirow{2}{*}{$\frac{\text { Total favorable probability }}{P_{i} \times 10^{4}}$} & \multirow[b]{2}{*}{ Rank } \\
\hline & $d$ & $h$ & $l$ & $\Delta t(\mathrm{~mm})$ & $F_{\max }(\mathrm{kN})$ & $P_{\max }(\mathrm{MPa})$ & $P_{i j}$ for $\Delta t$ & $P_{i j}$ for $F_{\max }$ & $P_{i j}$ for $P_{\max }$ & & \\
\hline 14 & 4 & 2 & 3 & 0.034 & 110 & 582 & 0.0491 & 0.0536 & 0.0503 & 1.3232 & 14 \\
\hline 15 & 4 & 3 & 2 & 0.041 & 87 & 465 & 0.0358 & 0.0701 & 0.0650 & 1.6321 & 11 \\
\hline 16 & 4 & 4 & 1 & 0.049 & 65 & 327 & 0.0208 & 0.0858 & 0.0823 & 1.4653 & 13 \\
\hline
\end{tabular}

Furthermore, Tab. 11 presents the results of range analysis of the total favorable probabilities for the orthogonal test design of optimization on extrusion process for joint bearing.

Table 11 Results of range analysis of the total favorable probabilities for the orthogonal test design of optimization on extrusion process for joint bearing

\begin{tabular}{|c|c|c|c|}
\hline Level & $d$ & $h$ & $l$ \\
\hline 1 & 3.3815 & 1.6830 & 2.5483 \\
\hline 2 & 2.9510 & 2.2810 & 2.4123 \\
\hline 3 & 2.1580 & 2.7237 & 2.4863 \\
\hline 4 & 1.2712 & 3.0740 & 2.3147 \\
\hline Range & 2.1103 & 1.3909 & 0.2337 \\
\hline Order & 1 & 2 & 3 \\
\hline
\end{tabular}

From range analysis of the data in Tab. 11, it shows that the order of the input variables for impact decreasing is from $d, h$ to $l$. The optimal combination is $d_{1} h_{4} l_{1}$, which coincides with the result of the complex comprehensive balance method in the multi-objective orthogonal test design accidentally [11]. The FEM simulation test indicates that the corresponding bearing crevice $\Delta t$ is $0.04 \mathrm{~mm}$, the maximum extrusion force $F_{\max }$ and the maximum contact pressure $P_{\max }$ of liner decreased by $47.3 \%$ and $65.6 \%$ as compared to the previous condition before optimization [11], respectively, which reflects the validity of the optimization.

\subsection{Multi-objective robust optimization of injection molding process parameters based on TOPSIS and uniform experimental design}

Cheng et al dealt with the problems of multi-objective robust optimization of injection molding process parameters based on technique for order preference by similarity to ideal solution (TOPSIS) and uniform experimental design for mobile phone panel [14]. The volume shrink rate $\phi_{\mathrm{shr}}(\%)$, sink index $I_{\text {sink }}(\%)$, buckling deformation W (mm) were taken as the objective indicators, and the input variables include melt temperature, injection time and packing pressure while keeping injection pressure of $100 \mathrm{MPa}$, packing time of $3 \mathrm{~s}$ and the cooling time of $5 \mathrm{~s}$, then the uniform experimental design was conducted.

Tab. 12 multi-objective robust optimization of injection molding process parameters based on TOPSIS and uniform experimental design [14].

Table 12 Uniform experimental design $\mathrm{U}_{10}\left(5^{3}\right)$ for the optimization [14]

\begin{tabular}{|l|c|c|c|c|c|}
\hline \multirow{2}{*}{ Factors } & \multicolumn{5}{|c|}{ Levels } \\
\cline { 2 - 6 } & 1 & 2 & 3 & 4 & 5 \\
\hline Melt temperature $X_{1}\left({ }^{\circ} \mathrm{C}\right)$ & 265 & 270 & 275 & 280 & 285 \\
\hline Injection time $X_{2}(\mathrm{~s})$ & 0.50 & 0.55 & 0.60 & 0.65 & 0.70 \\
\hline Packing pressure $X_{3}(\mathrm{MPa})$ & 70 & 75 & 80 & 85 & 90 \\
\hline
\end{tabular}

Since the volume shrink rate $\phi_{\mathrm{shr}}$, sink index $I_{\text {sink }}$, buckling deformation $W$ are unbeneficial indicators to the technique optimization, therefore, Eqs. (3) and (4) are employed to perform the assessment for their partial favorable probability.

Tab. 13 presents the results of the partial and total favorable probabilities for the volume shrink rate $\phi_{\mathrm{shr}}$, sink index $I_{\text {sink, }}$ and buckling deformation $\mathrm{W}$ in the uniform experimental design.

In Tab. 13, the test 2 exhibits the maximum of the total favorable probability $P_{i}$, while the total favorable probability of test 1 is very close to the maximum total favorable probability $\mathrm{Pi}$, so they could be chosen as one of the optimal combination in the multi-objective uniform experimental design directly.

Table 13 Results of the multi-objective robust optimization of injection molding process parameters based on TOPSIS and uniform experimental design [14]

\begin{tabular}{|c|c|c|c|c|c|c|c|c|c|c|c|}
\hline No & $X_{1}$ & $X_{2}$ & $X_{3}$ & $\phi_{\mathrm{shr}}(\%)$ & $I_{\text {sink }}(\%)$ & W (mm) & $P_{i j}$ for $\phi$ & $P_{i j}$ for $I$ & $P_{i j}$ for $W$ & $P_{i} \times 10^{3}$ & Rank \\
\hline 1 & 2 & 5 & 5 & 6.037 & 3.230 & 0.4048 & 0.1084 & 0.1140 & 0.1074 & 1.3279 & 2 \\
\hline 2 & 4 & 1 & 5 & 6.200 & 3.393 & 0.3735 & 0.1059 & 0.1097 & 0.1144 & 1.3297 & 1 \\
\hline 3 & 5 & 2 & 2 & 6.895 & 4.057 & 0.4306 & 0.0953 & 0.0920 & 0.1016 & 0.8917 & 6 \\
\hline 4 & 4 & 5 & 1 & 6.937 & 4.090 & 0.4695 & 0.0947 & 0.0911 & 0.0929 & 0.8020 & 7 \\
\hline 5 & 3 & 3 & 3 & 6.587 & 3.744 & 0.4314 & 0.1000 & 0.1003 & 0.1015 & 1.0182 & 5 \\
\hline 6 & 2 & 1 & 1 & 7.114 & 4.286 & 0.5103 & 0.0921 & 0.0860 & 0.0838 & 0.6622 & 9 \\
\hline 7 & 5 & 4 & 4 & 6.299 & 3.471 & 0.3815 & 0.1045 & 0.1076 & 0.1126 & 1.2658 & 3 \\
\hline 8 & 3 & 3 & 3 & 6.587 & 3.744 & 0.4314 & 0.1000 & 0.1003 & 0.1016 & 1.0184 & 5 \\
\hline 9 & 1 & 2 & 4 & 6.463 & 3.614 & 0.4406 & 0.1019 & 0.1038 & 0.0994 & 1.0516 & 4 \\
\hline 10 & 1 & 4 & 2 & 6.777 & 3.938 & 0.5054 & 0.0971 & 0.0952 & 0.0849 & 0.7846 & 8 \\
\hline
\end{tabular}

Cheng et al gave a test result of pack pressure $P=90$ $\mathrm{MPa}$, injection time $=0.7 \mathrm{~s}$ and melt temperature $\theta_{\text {melt }}=275$ ${ }^{\circ} \mathrm{C}$, it is in fact with a compromised parameters of the tests 1 and 2 [14], which exhibits smaller volume shrink rate $\phi_{\text {shr, }}$, sink index $I_{\text {sink }}$ and buckling deformation $W$ and implies the validity of the novel assessment.

\section{DISCUSSION}

From above study, it can be seen that the new "intersection" method for multi-objective optimization in material selection on basis of set theory and probability theory treats both beneficial property index and unbeneficial property index equivalently and conformably, which is 
impersonal without any personal or subjective scaling factor.

The evaluation results for material selection for a rectangular beam, automotive piston design, automotive brake pad and polymeric nano-composite material for automotive bumper beam, the multi-objective orthogonal test design and uniform experimental design are all acceptable and conform to known, which indicates the reasonability of the new "intersection" method.

The evaluation result of the new "intersection" method for multi-objective optimization in material selection is not needed to equal to other previous approaches exactly due to the utilization of personal coefficients or other subjective factors in the latter.

\section{CONCLUSION}

Through this study, a new "intersection" method for multi-objective optimization in material selection is developed based on the probability analysis for all possible material property indicators comprehensively. All the material property indicators are divided into beneficial type and unbeneficial (cost) type; each material property indicator contributes to its partial favorable probability in positively correlative or negatively correlative manner, individually. The total favorable probability of a candidate material is the product of its all possible partial favorable probabilities. The total favorable probability of a candidate material determines the final result of the material selection decisively and comprehensively.

\section{Conflict Statement}

There is no conflict of interest.

\section{REFERENCES}

[1] Farag, M. M. \& EI-Magd, E. (1992). An integrated approach to product design, materials selection and cost estimation. Materials \& Design, 13, 323-327. https://doi.org/10.1016/0261-3069(92)90001-X

[2] Farag, M. M. (2021). Materials and Process Selection for Engineering Design, $4^{\text {th }}$ Edition, CRC Press, Taylor \& Francis Group.

[3] Ashby, M. F. (1992). Materials Selection in Mechanical Design, Butterworth - Heinemann Ltd, Exeter.

[4] Jahan, A. \& Edwards, K. L. (2015). A state - of - the - art survey on the influence of normalization techniques in ranking: Improving the materials selection process in engineering design. Materials and Design, 65, 335-342. https://doi.org/10.1016/j.matdes.2014.09.022

[5] Opricovic, S. \& Tzeng, G. H. (2004). Compromise solution by MCDM methods: A comparative analysis of VIKOR and TOPSIS. Europ. J. of Operational Research, 156, 445-455. https://doi.org/10.1016/S0377-2217(03)00020-1

[6] Wang, P., Zhu, Z., \& Wang, Y. (2016). A novel hybrid MCDM model combining the SAW, TOPSIS and GRA methods based on experimental design. Information Sciences, 345, 27-45. https://doi.org/10.1016/j.ins.2016.01.076

[7] Brauers, W. K. M. \& Zavadskas, E. K. (2006). The MOORA method and its application to privatization in a transition economy. Control and Cybernetics, 35, 445-469.
[8] Brémaud, P. (2020). Probability Theory and Stochastic Processes, Universitext Series, Springer, Cham. 7-11. https://doi.org/10.1007/978-3-030-40183-2

[9] Maleque, M. A. \& Salit, M. S. (2013). Materials Selection and Design, Springer, Heidelberg, 81-83. https://doi.org/10.1007/978-981-4560-38-2

[10] Hasanzadeh, R., Azdast, T., Eungkee Lee, R., \& Afsari Ghazi, A. (2017). Experimental polymeric nano-composite material for automotive bumper beam by using multi-criteria decision making methods. Iranian J. of Materials Science \& Eng., 14(3), $1-10$.

[11] Xin, L., Wang, X., \& Huang, X. (2019). Multi-objective optimization design on extrusion process for joint bearing. Forging \& Stamping Technology, 44(7), 79-85.

[12] Obara, C., Mwema, F. M., Keraita, J. N., Shagwira, H., \& Obiko, J. O. (2021). A Multi - response optimization of the multi-directional forging process for aluminum 7075 alloy using grey-based Taguchi method. SN Applied Science, 3(596), 1-20. https://doi.org/10.1007/s42452-021-04527-2

[13] Teruo, M. (2011). Taguchi Methods, Benefits, impacts, Mathematics, Statistics, and Applications, ASME Press, New York, 7-204.

[14] Cheng, J., Tan, J., \& Yu, J. (2011). Multi-objective robust optimization of injection molding process parameters based on TOPSIS. Journal of Mechanical Engineering, 47, 27-32. https://doi.org/10.3901/JME.2011.06.027

\author{
Authors' contacts: \\ Maosheng Zheng \\ (Corresponding author) \\ School of Chemical Engineering, Northwest University, \\ No. 229, Taibai North Road, Xi'an, 710069, Shaanxi Province, China \\ E-mail: mszhengok@aliyun.com \\ Yi Wang \\ School of Chemical Engineering, Northwest University, \\ No. 229, Taibai North Road, Xi'an, 710069, Shaanxi Province, China \\ Haipeng Teng \\ School of Chemical Engineering, Northwest University, \\ No. 229, Taibai North Road, Xi'an, 710069, Shaanxi Province, China
}

